\title{
Anticomplement therapy
}

\author{
Prathit A Kulkarni' \\ Vahid Afshar-Kharghan ${ }^{2}$ \\ 'Baylor College of Medicine, Houston, \\ Texas, USA; ${ }^{2}$ The University of Texas, \\ M.D. Anderson Cancer Center, \\ Houston, Texas, USA
}

\begin{abstract}
The complement system is an important part of innate immunity; however, as with other parts of the immune system, the complement system can become pathologically activated and create or worsen disease. Anticomplement reagents have been studied for several years, but only recently have they emerged as a viable therapeutic tool. Here, we describe the role of the complement system in a wide array of diseases, as well as the use of anticomplement therapy as treatment for these diseases in animal models and in human clinical trials. Specifically, we will discuss the role of anticomplement therapy in paroxysmal nocturnal hemoglobinuria, glomerulonephritis, and heart disease, including coronary artery disease, myocardial infarction, and coronary revascularization procedures such as percutaneous coronary angioplasty and coronary artery bypass graft surgery.
\end{abstract}

Keywords: complement, paroxysmal nocturnal hemoglobinuria, glomerulonephritis, myocardial infarction, cardiopulmonary bypass

\section{Introduction}

The complement system, as a part of innate immunity, carries out a wide array of functions, including protection against foreign organisms, removal of immune complexes from the circulation, and clean-up of cellular debris which accumulates over time. The complement system also plays a significant role in the initiation and propagation of the inflammatory response. Besides its beneficial effect, though, the complement system can also play a detrimental role in many pathologic conditions.

The complement system comprises several plasma and cell surface proteins, including complement regulatory proteins. When these complement regulatory proteins do not function properly, the complement system can become improperly activated and cause tissue damage. Over the last several years, a significant amount of work has been done to study complement activation in certain disease states and whether there is any role for complement inhibition in the treatment of these diseases. In this paper, we will review the function and regulation of the complement system, give a brief description of various complement inhibitors, and discuss the recent use of anticomplement therapeutics in specific diseases, namely paroxysmal nocturnal hemoglobinuria, glomerulonephritis, and heart disease, including coronary artery disease, myocardial infarction, and cardiac surgery requiring the use of cardiopulmonary bypass.

\section{Overview of the complement system Activation of the complement system}

The complement system comprises more than 30 plasma proteins, most of which are synthesized by the liver. The complement system acts through three major pathways, the classical pathway, activated by antigen-antibody complexes; the alternative pathway, activated spontaneously by attachment of $\mathrm{C} 3 \mathrm{~b}$ to a particular surface; and the lectin pathway, activated by the binding of mannan-binding lectins to carbohydrate ligands on the surface of pathogens (Figure 1) (Janeway et al 1999; Qin and Gao 2006; 


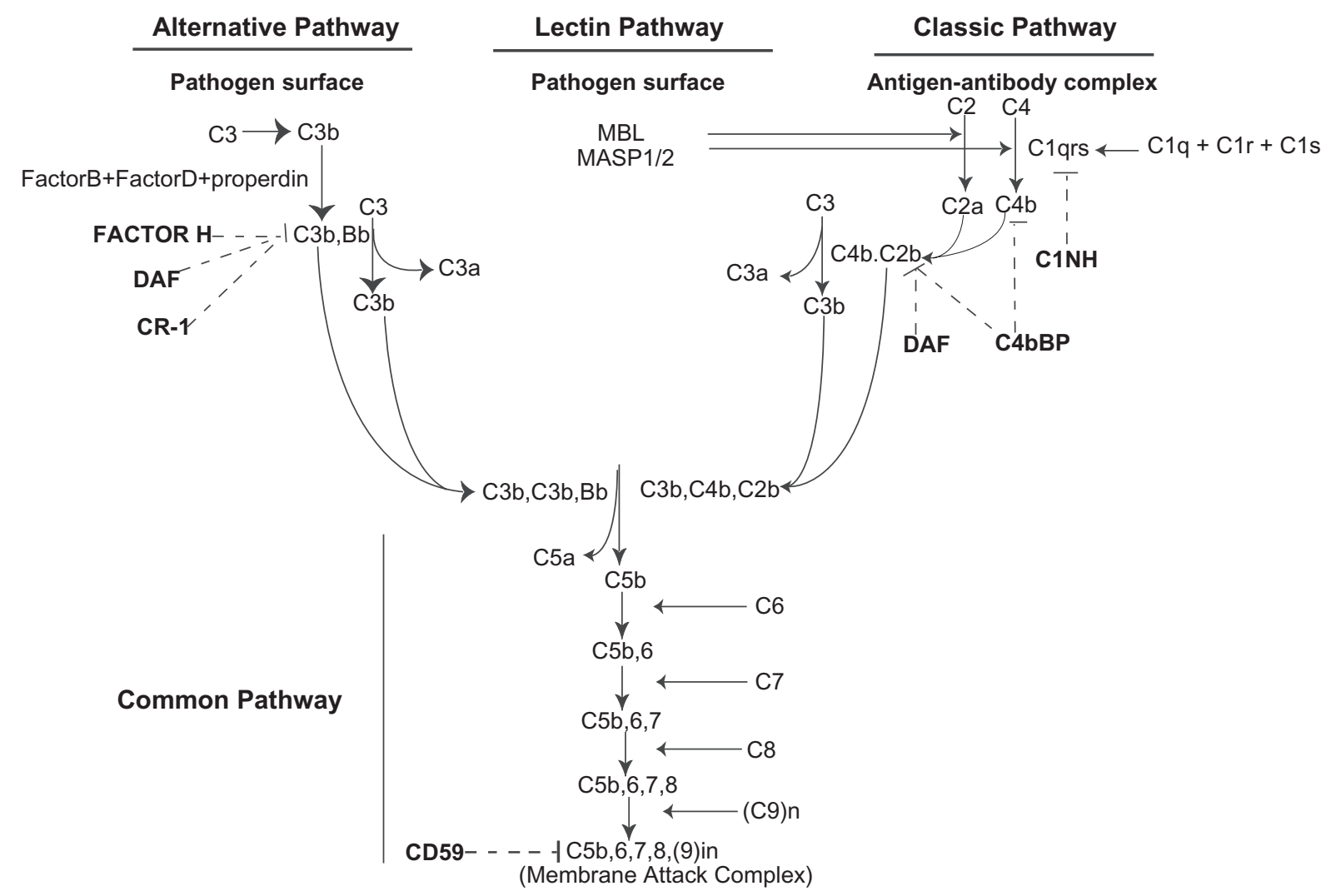

Figure I Activation pathways of the complement system and complement regulatory proteins. Three pathways of activation of the complement system (the classical, alternative and lectin pathways), their convergence on a common pathway, and the components of each pathway are depicted. The effect of different complement regulatory proteins is shown as dashed lines.

Abbreviations: MBL, mannan-binding lectin; MASPI/2, MBL-associated serine protease I and 2; $\mathrm{CIINH}, \mathrm{Cl}$ inhibitor; $\mathrm{C} 4 \mathrm{bBP}, \mathrm{C} 4 \mathrm{~b}$ binding protein, $\mathrm{DAF}$, decay accelerating factor, CR-I, complement receptor I.

Cummings et al 2007; Oksjoki et al 2007). The central convergence point of all three pathways is the formation of a $\mathrm{C} 3$ convertase on the surface of a particular cell. With the formation of a functioning $\mathrm{C} 3$ convertase, complement is able to carry out its effector functions (Figure 2).

In the classical pathway, C1q, one of the subunits of $\mathrm{C} 1$, first binds to the $\mathrm{F}_{\mathrm{c}}$ domains of antibodies attached to their antigen. Another subunit of C1, C1r, cleaves and activates the third subunit of $\mathrm{C} 1, \mathrm{C} 1 \mathrm{~s}$. Activated $\mathrm{C} 1 \mathrm{~s}$ cleaves $\mathrm{C} 4$ and $\mathrm{C} 2$ to form $\mathrm{C} 4 \mathrm{~b}$ and $\mathrm{C} 2 \mathrm{~b}$, respectively, which then combine to form the $\mathrm{C} 3$ convertase of the classical complement pathway (Figure 1). Similarly, in the lectin pathway, cleavage of $\mathrm{C} 4$ and $\mathrm{C} 2$ allow formation of the $\mathrm{C} 3$ convertase. In the alternative pathway, C3 is spontaneously cleaved to $\mathrm{C} 3 \mathrm{a}$ and $\mathrm{C} 3 \mathrm{~b}$. $\mathrm{C} 3 \mathrm{~b}$ covalently binds to cell surfaces and with the help of factor $\mathrm{B}$ (FB) and factor $\mathrm{D}$ (FD) can form the $\mathrm{C} 3 \mathrm{bBb}$ complex, which is the alternative pathway's $\mathrm{C} 3$ convertase (Figure 1).

The function of the $\mathrm{C} 3$ convertase in all three pathways is to further cleave $\mathrm{C} 3$, producing $\mathrm{C} 3 \mathrm{a}$, one of the two major anaphylatoxins of the complement system, and $\mathrm{C} 3 \mathrm{~b}$, a potent opsonin. Binding of several $\mathrm{C} 3 \mathrm{~b}$ molecules to cells and other debris marks them for phagocytosis by macrophages. Propagation of complement activation by the $\mathrm{C} 3$ convertase results in the generation of a $\mathrm{C} 5$ convertase on cell surfaces. The function of the $\mathrm{C} 5$ convertase is to cleave C5 to C5a and $\mathrm{C} 5 \mathrm{~b}$. C5a is the other anaphylatoxin and is much more potent than $\mathrm{C} 3 \mathrm{a}$. As anaphylatoxins, $\mathrm{C} 3 \mathrm{a}$ and $\mathrm{C} 5 \mathrm{a}$ are able to recruit neutrophils to areas of inflammation and damage. $\mathrm{C} 5 \mathrm{~b}$ is subsequently able to bind to $\mathrm{C} 6, \mathrm{C} 7, \mathrm{C} 8$, and $\mathrm{C} 9$ to form the membrane attack complex (MAC or C5b-9 complex). The C5b-9 complex is able to disrupt the phospholipid bilayer of the cell membrane, leading to loss of cellular homeostasis and eventual cell death (Figure 2).

Thus, the three main functions of the complement system are opsonization of pathogens or other molecules, which targets them for eventual destruction, augmentation of inflammation by the recruitment of inflammatory cells via the anaphylatoxins $\mathrm{C} 3 \mathrm{a}$ and $\mathrm{C} 5 \mathrm{a}$, and direct killing of cells by the formation of MACs (Figure 2). 


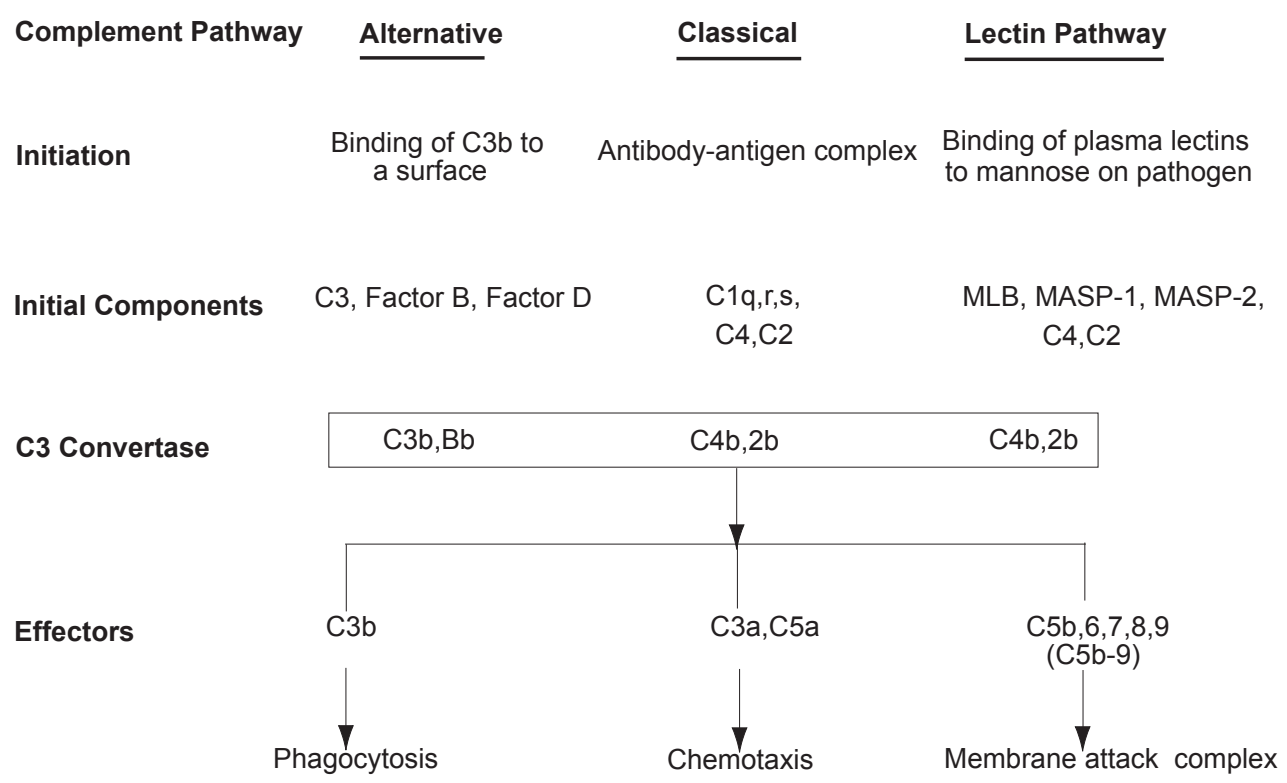

Figure $\mathbf{2}$ The complement system and its effectors.

\section{Regulation of the complement system}

Because the complement system has such a potent ability to cause cellular damage, it is extensively regulated both in the fluid phase and on cell surfaces. We will briefly describe the major complement regulatory proteins.

In the classical pathway, one of the main complement regulatory proteins is $\mathrm{C} 1$ inhibitor (C1-INH), which binds to the $\mathrm{C} 1 \mathrm{r}: \mathrm{C} 1 \mathrm{~s}$ complex and causes it to dissociate from $\mathrm{C} 1 \mathrm{q}$, thus preventing activation of the complement system. The function of the other major complement regulatory proteins can be categorized under two major activities: (1) breaking up the $\mathrm{C} 3$ convertase, termed decay-accelerating activity and (2) cleavage of either $\mathrm{C} 3 \mathrm{~b}$ or $\mathrm{C} 4 \mathrm{~b}$ to their inactive forms, iC $3 \mathrm{~b}$ and $\mathrm{iC} 4 \mathrm{~b}$, respectively, termed membrane co-factor activity. Proteins with decay-accelerating activity which regulate the classical pathway include C4-binding protein (C4bp), complement receptor 1 (CR1), and decay-accelerating factor (DAF) or CD55. Proteins with decay-accelerating activity which regulate the alternative pathway include CR1, factor $\mathrm{H}(\mathrm{FH})$, and DAF (Figure 1).

All membrane co-factor activity relies on the function of a serine protease known as factor I (FI). Factor I, in turn, requires at least one of several potential co-factors to degrade $\mathrm{C} 3 \mathrm{~b}$ and $\mathrm{C} 4 \mathrm{~b}$. For the classical pathway, proteins with membrane co-factor activity include C4bp, CR1, and membrane co-factor protein (MCP), while those for the alternative pathway are $\mathrm{CR} 1, \mathrm{FH}$, and MCP.

Another important regulatory protein is CD59, also known as protectin. CD59 prevents formation of the C5b-9 complex (MAC) on cell surfaces and is highly expressed on cell membranes throughout the body.

\section{Development of complement inhibitors}

The first complement inhibitor described in the scientific literature was cobra venom factor (CVF). The anticomplement activity of cobra venom was described by Flexner and Noguchi in 1903 (Flexner and Noguchi 1903). It was not until the late 1960's and early 1970's that the component of cobra venom responsible for its anticomplement activity was recognized (Gewurz et al 1967; Maillard and Zarco 1968; Cochrane et al 1970; Phillips 1970; Muller-Eberhard and Fjellstrom 1971). CVF binds to mammalian FB in plasma and after cleavage of FB by FD, a stable, soluble C3 convertase is produced, the CVF-Bb complex (Cooper 1973). The CVF-Bb complex consumes $\mathrm{C} 3$ in the plasma very efficiently; in fact, a single injection of CVF can completely eliminate complement activity for 24-72 hours in certain animal models (Morgan and Harris 2003).

One of the first synthetic molecules to be developed for anticomplement therapy was nafamastat mesilate, also known as FUT-175. This molecule inhibits C1r, C1s, C3 convertase, C5 convertase, and FD (Fujii and Hitomi 1981; Inagi et al 1991). Nafamastat mesilate is not entirely complement-specific, however, and can inhibit several other plasma proteases (Hitomi and Fujii 1982).

Using phage display random peptide libraries, several complement inhibitors have been discovered. Compstatin, which 
is composed of only 13 amino acid residues, binds to $\mathrm{C} 3$ and inhibits its cleavage by C3 convertase (Sahu et al 1996). Molecules blocking $\mathrm{C} 1 \mathrm{q}$ in vitro have also been obtained from random peptide libraries (Roos et al 2001).

Interestingly, heparin has long been known to possess anticomplement properties (Weiler et al 1978). Its effects include binding to and subsequent inactivation of $\mathrm{C} 1$, inhibition of MAC assembly, and blockage of the formation of C3 convertase (Baker et al 1975; Hughes-Jones and Gardner 1978; Almeda et al 1983; Weiler 1983).

Another category of complement inhibitors is recombinant proteins that are engineered using genes encoding membrane complement regulatory proteins. These recombinant proteins have been genetically modified to make them soluble so that they inhibit complement activation in the fluid phase. One of the first recombinant complement inhibitors was soluble CR1 (sCR1), also known as TP10. Weisman et al developed this molecule, which comprises the entire extracellular domain of CR1, and showed that it inhibited formation of C3 and C5 convertases in vivo (Weisman et al 1990a, 1990b). Soluble recombinant MCP and DAF have also been developed and have been shown to inhibit complement both in vitro and in vivo (Moran et al 1992; Christiansen et al 1996). A hybrid molecule named complement activation blocker-2 (CAB-2) was designed by fusing the functional domains of $\mathrm{MCP}$ and DAF (Higgins et al 1997). In vitro CAB-2 was shown to inhibit complement activation (Kroshus et al 2000).

Another logical approach to inhibition of the complement system is to use a blocking antibody against one of the many interacting complement proteins. N19-8, the first anticomplement monoclonal blocking antibody developed, was shown to block C5 cleavage in vitro (Wurzner et al 1991). Subsequently, a second antibody to human C5, termed h5G1.1, was developed (Kroshus et al 1995). This molecule was modified to have only single-chain Fv fragments but still retain full antiC5 activity (Thomas et al 1996).

Using recombinant DNA technologies, investigators became able to combine complement-binding antibodies to inhibitory domains of complement regulatory proteins. There are two different ways in which these hybrid molecules have been designed. One way is to use the $\mathrm{F}_{\mathrm{ab}}$ portion (the antigenbinding fraction) of the antibody to direct the molecule toward a particular cell membrane component, while the $\mathrm{F}_{\mathrm{c}}$ portion (the constant fraction) is the soluble complement regulator itself. Two examples of hybrid molecules created in this way are antidansyl $\mathrm{F}_{\mathrm{ab}}$ arms fused with either CD59 or DAF (Zhang et al 1999, 2001). Both fusion proteins were able to avidly bind to dansyl-labeled Chinese hamster ovary cells. Another way to fuse antibody fragments to soluble complement inhibitors is to use the complement inhibitors themselves as the $\mathrm{F}_{\mathrm{ab}}$ arms of the molecule and to use the normal $F_{c}$ portion of the antibody to keep the molecules in the circulation longer (Pugsley 2001). One downside to this approach is reduced activity of the hybrid molecule as compared to a pure soluble complement inhibitor, perhaps due to a steric hindrance (Harris et al 2002).

\section{Complement inhibition as therapy for disease}

The possibility of complement inhibition as therapy for various disease states has been studied in organ transplantation, ischemia-reperfusion injury, coronary artery disease, myocardial infarction, stroke, infection, cancer, immunosuppression, paroxysmal nocturnal hematuria, glomerulonephritis, rheumatoid arthritis, and acute respiratory distress syndrome, and has also been used in the coating of extracorporeal circuits in cardiopulmonary bypass and dialysis (Table 1). Any possible benefit from inhibiting the complement system should be balanced with potential side effects, such as an increased susceptibility to infection with encapsulated bacteria, Neisseria meningitidis in particular, and autoimmune diseases caused by decreased clearance of immune complexes. In this review, we will focus on anticomplement therapy in paroxysmal nocturnal hemoglobinuria, glomerulonephritis, coronary artery disease, myocardial infarction, and cardiac surgery requiring cardiopulmonary bypass.

\section{Paroxysmal nocturnal hemoglobinuria Overview and pathophysiology}

Paroxysmal nocturnal hemoglobinuria (PNH) is a clonal disorder due to an acquired somatic mutation in the X-linked phosphatidylinositol glycan complementation class $\mathrm{A}(P I G-A)$ gene, which leads to a partial or complete deficiency of all proteins which are usually linked to the cell membrane via a glycosyl phosphatidylinositol (GPI) anchor (Takeda et al 1993; Bessler et al 1994). DAF and CD59, complement regulatory proteins, are two GPI-anchored molecules; therefore, PNH cells have a deficiency of DAF and/or CD59 on their cell membrane and are more susceptible to destruction by complement. The proportion of normal stem cells and PNH stem cells in any one patient can vary, but PNH cells usually constitute the majority of hematopoietic cells (Richards et al 2007). The clinical features of PNH include intravascular hemolysis, bone marrow failure, and a predisposition to thrombosis 
Table I Summary of anticomplement therapy used in clinical trials

\begin{tabular}{lll}
\hline Clinical situation & Principle of anticomplement therapy & Treatment \\
\hline $\begin{array}{l}\text { Paroxysmal nocturnal hemoglobinuria } \\
\text { Paroxysmal nocturnal hemoglobinuria }\end{array}$ & $\begin{array}{l}\text { C5 inhibition } \\
\text { Replacement of deficient complement } \\
\text { inhibitor molcule } \\
\text { Glomerulonephritis }\end{array}$ & $\begin{array}{l}\text { Eculizumab (monoclonal antibody) } \\
\text { Recombinant soluble CD59 }\end{array}$ \\
AMI treated with thrombolysis & $\begin{array}{l}\text { Augmentation of complement inhibitory } \\
\text { molecules }\end{array}$ & Eculizumab \\
AMI treated with thrombolysis & C5 inhibition & Pexelizumab (monoclonal antibody) \\
AMI treated with angioplasty & C5 inhibition & Pexelizumab (monoclonal antibody) \\
AMI treated with CABG surgery & Augmentation of complement inhibitory & CI inhibitor \\
molecules & Augmentation of complement inhibitory & TPI0 (recombinant soluble complement receptor I) \\
Cardiac surgery requiring CPB & molecules & Heparin \\
Cardiac surgery requiring CPB & Inhibition of the complement system at & Pexelizumab (monoclonal antibody)
\end{tabular}

Abbreviations: $C A B G$, coronary artery bypass graft; $A M I$, acute myocardial infarction; $C P B$, cardiopulmonary bypass; $C D$, cluster of differentiation.

(Hillmen et al 1995; Socie et al 1996). Patients usually have acute severe hemolytic episodes with a chronic mild hemolysis in the background (Hill et al 2007). Despite the extensive hemolysis, the major cause of morbidity and mortality in PNH is venous thrombosis, which occurs in about $50 \%$ of patients and is responsible for one-third of deaths in PNH (Hillmen et al 1995; Socie et al 1996). The cause of PNH patients' predilection to thrombosis is currently unknown (Hill et al 2007). While venous thrombosis is the major cause of morbidity and mortality in $\mathrm{PNH}$, many patients also develop pancytopenia due to aplastic anemia (Hill et al 2007). The median survival of patients with PNH from the time of diagnosis is about $10-15$ years. However, approximately $15 \%$ of patients experience spontaneous regression of PNH with no residual sequelae (Hillmen et al 1995).

\section{Therapy}

Standard therapy for PNH includes supportive care with red blood cell (RBC) transfusions and treatment of thrombotic complications (Hill et al 2007). The only definitive cure for PNH currently is allogeneic bone marrow transplantation (BMT), with indications for this similar to the indications for BMT in aplastic anemia.

In the past several years, studies have been conducted on the humanized monoclonal antibody eculizumab (Alexion Pharmaceuticals, Soliris, Cheshire, Connecticut, USA), which is directed against human C5 (Thomas et al 1996). In 2004, a pilot study using 11 patients with PNH was conducted in which the patients received infusions of eculizumab over a period of 12 weeks (Hillmen et al 2004). In this small study, mean lactate dehydrogenase (LDH) levels decreased significantly over the course of the study; the percentage of PNH erythrocytes increased significantly; transfusion rates declined; and the occurrence of hemoglobinuria subsided dramatically. All of the patients from this study chose to participate in a 52-week extension of the study, in which they received eculizumab infusions every 12-14 days (Hill et al 2005a). The findings from the initial pilot study all held up during the follow-up study, with the addition of quality-oflife measurements being significantly improved. It was also shown through this study that long-term eculizumab therapy is safe and well tolerated. In a study of two patients treated with eculizumab, intravascular hemolysis decreased, and symptoms associated with smooth muscle dystonia, such as abdominal pain, dysphagia, and erectile dysfunction, were also significantly reduced (Hill et al 2005b).

All of this work provided the impetus for a future study involving larger numbers of patients in a double-blind, randomized, placebo-controlled phase III trial, termed the Transfusion Reduction Efficacy and Safety Clinical Investigation, a Randomized, Multicenter, Double-Blind, PlaceboControlled, Using Eculizumab in Paroxysmal Nocturnal Hemoglobinuria (TRIUMPH) study (Hillmen et al 2006). Eighty-seven patients were given either $600 \mathrm{mg}$ eculizumab or placebo on a weekly basis for 4 weeks, then a $900 \mathrm{mg}$ dose one week later, then $900 \mathrm{mg}$ every other week up to 26 weeks. The primary end points were the hemoglobin level and how many units of blood the patients needed during 
the period of time of the study. Hemoglobin stabilization without transfusion occurred in 21 of 43 patients in the eculizumab group, while it occurred in 0 of 44 patients in the placebo group. A median of 10 units of blood were given to the placebo group during the study period, while the group receiving eculizumab required 0 units. In addition, the eculizumab group had a significant decrease in LDH levels as well as a significant increase in quality of life.

In a multinational open-label extension study of the TRIUMPH study using 195 patients, the same authors studied the effect of eculizumab on the occurrence of thromboembolism (TE) (Hillmen et al 2007). Prior to treatment, the TE event rate was 7.37/100 patient-years, whereas with treatment, the rate was $1.07 / 100$ patient-years. It was thus concluded that treatment with eculizumab in PNH significantly reduces the occurrence of TE.

Another possible option for the treatment of $\mathrm{PNH}$ is recombinant soluble $\mathrm{CD} 59$, since this is one of the critical membrane-bound proteins deficient in $\mathrm{PNH}$. In vitro studies with human $\mathrm{PNH}$ erythrocytes showed that recombinant soluble CD59 was able to bind to the surface of RBCs at levels sufficient to inhibit complement-mediated hemolysis (Hill et al 2006). In an in vivo experiment, the RBCs of mice given recombinant soluble CD59 were partially protected from complement-mediated destruction. In a similar experiment, a single-chain antibody variable region fragment targeted against TER-119, a mouse RBC antigen, was attached to human DAF (Spitzer et al 2004). This recombinant protein was able to bind to mouse RBCs in vivo and protect them from complement-mediated destruction.

\section{Glomerulonephritis}

\section{Overview and pathophysiology}

The basic pathophysiology of glomerulonephritis is inflammation of the glomerulus, and the main clinical features of the various glomerulonephritides include proteinuria, hematuria, and decreased glomerular function (Javaid and Quigg 2005). End-stage renal disease can be the eventual outcome of glomerulonephritis, which leaves patients dependent on chronic dialysis and/or renal transplantation.

The complement system can play a significant role in the inflammation of glomerulonephritis. For example, greater than $80 \%$ of patients with Type II membranoproliferative glomerulonephritis (MPGN) are positive for serum C3-nephritic factor, an antibody against $\mathrm{C} 3 \mathrm{bBb}$ which inhibits the dissociation of Bb from C3b (Daha et al 1976; Schwertz et al 2001). In patients with IgM nephropathy, serum C3 levels are directly correlated with proteinuria and progression of the disease (Myllymäki et al 2006).

The important role of the complement system in the development of different glomerular diseases has been shown in several animal models. Mice deficient in FH develop Type II MPGN with deposition of C3 in the capillary walls (Pickering et al 2002). Of interest, mice deficient in FH and C5 developed less severe disease than those only deficient in FH (Pickering et al 2006).

Mice deficient in either DAF or DAF and CD59 had an increased incidence of immune-complexmediated glomerulonephritis with increased glomerular deposition of C3 (Bao et al 2007). In a mouse model of immune-complex-mediated glomerulonephritis, CD59-deficient mice had more proteinuria (Turnberg et al 2003). Similarly, DAF-deficient mice and DAFand CD59-combined knockout mice had much worse albuminuria in a model of nephrotoxic serum-induced nephritis (Lin et al 2004).

In another mouse model of progressive glomerlonephritis, $\mathrm{C} 5 \mathrm{a}$ receptor $(\mathrm{C} 5 \mathrm{aR})$-deficient mice showed less interstitial damage than control mice (Welch et al 2002). Similarly, in a mouse model of lupus nephritis, a synthetic anti-C5a receptor molecule (a cyclic hexapeptide) led to less decline in renal function, as well as decreased infiltration of kidneys by neutrophils and macrophages (Bao et al 2005).

Despite the etiologic role of the complement system in the pathogenesis of the majority of the glomerulonephritides, in some cases, a functional complement system might play a protective role against the development of glomerulonephritis. For example, factor D-deficient mice, which lack the alternative complement system, developed immune-complex glomerulonephritis (specifically Type II rapidly progressive glomerulonephritis) and showed mesangial deposition of IgM (Abrera-Abeleda et al 2007). Complement activity is necessary for the clearance of immune complexes from the body, and lack of this clearance activity due to a deficiency in complement activity might contribute to the development of glomerulonephritis. Another example of complement's protective role in glomerulonephritis is that deficiencies in $\mathrm{C} 1 \mathrm{q}, \mathrm{C} 2$, or $\mathrm{C} 4$ predispose humans to the development of systemic lupus erythematosus (SLE) and lupus nephritis (Mitchell et al 2002). Presence of anti-C1q antibodies, resulting in the lack of a functional classical complement pathway, predicts with relatively high sensitivity and specificity the presence of active lupus nephritis (Moroni et al 2001; Trendelenburg et al 2006). 
Anti-C 1q antibodies are present in $30 \%-40 \%$ of patients with SLE (Seelen et al 2003).

One might conclude based on these various, then, that the early components of the complement system are probably necessary for normal homeostasis of the immune system and that their absence may predispose to the development of immune-complex disease. Thus, targeting later components of the complement system for anticomplement therapy in glomerulonephritis may be the best option (Berger and Daha 2007).

\section{Therapy}

The clinical trials of anticomplement agents in patients with kidney disease have been much more limited than those in PNH patients. Nonetheless, many in vitro experiments and animal studies have been conducted in various types of glomerulonephritis. Couser et al studied complement inhibition in three different animal models of complementmediated glomerulonephritis (Couser et al 1995). In these models, administration of sCR1 was able to reduce the morphologic and functional characteristics of renal disease, as measured by mesangiolysis, glomerular infiltration by platelets and macrophages, and proteinuria.

In a mouse model of immune-complex-mediated glomerulonephritis, a monoclonal antibody against $\mathrm{C} 5$, BB5.1, was able to lessen renal disease and prolong survival (Wang et al 1996). The same antibody was also able to reduce proteinuria and renal damage in mice subjected to human antidouble-stranded DNA (Ravirajan et al 2004). In a mouse model of antimyeloperoxidase IgG-induced glomerulonephritis, administration of anti-C5 antibody (BB5.1) thwarted the development of glomerular disease, as shown by decreased hematuria, pyuria, albuminuria, and glomerular neutrophil infiltration (Huugen et al 2007).

In a multicenter, randomized, placebo-controlled phase II trial conducted in the US on 122 patients with idiopathic membranous nephropathy, treatment with eculizumab did not decrease urinary protein excretion, the primary outcome goal of the study (Appel et al 2002). However, there was some benefit with eculizumab in the open-label extension of the study. Currently, there is an ongoing trial with eculizumab in patients with membranous nephropathy; the results of this trial are still pending (Berger et al 2005; Javaid and Quigg 2005; Brown et al 2007).

\section{Coronary heart disease}

Coronary artery disease (CAD) is one of the most common causes of morbidity and mortality in the United States and the world at large. A significant amount of work has been done to better understand the role of the complement system in the pathology and pathophysiology of atherosclerosis and myocardial infarction (MI). This work has culminated in several clinical trials which have tested anticomplement therapy in the setting of acute myocardial infarction (AMI) and cardiac surgery.

\section{Stable coronary artery disease Overview and pathophysiology}

It has long been known that the complement system is involved in the development of CAD. For example, even in the late 1970's and throughout the 1980's, it was repeatedly shown that $\mathrm{C} 3$ is present in atherosclerotic plaques (Hollander et al 1979; Hansson et al 1984; Vlaicu et al 1985). Interestingly, complement regulatory proteins, including CR1, complement receptor 3, DAF, and CD59 are also present in atherosclerotic plaques, thus demonstrating activity and regulation of the complement system in atherosclerotic plaques (Seifert and Hansson 1989a, 1989b; Seifert et al 1992).

More recently, it was shown that C3 levels may be a good marker of insulin resistance, a risk factor for the development of diabetes mellitus (DM), and CAD (Muscari et al 2000). The level of $\mathrm{C} 3$ was a better predictor of blood pressure and glucose levels than the level of insulin itself. C3 levels also have an independent, significant correlation with fibrinogen levels, body mass indices, platelet counts (important for the development of thrombi), insulin levels, triglyceride (TG) levels, and levels of low-density lipoprotein cholesterol (Capuano et al 2006).

To our knowledge, no clinical trials using anticomplement therapies have been conducted in patients with stable CAD. However, we describe this work because it is relevant to potential clinical studies that could be done in patients with CAD.

\section{Acute myocardial infarction Overview and pathophysiology}

Involvement of the complement system in AMI has been shown since the 1970's. It was first observed that administration of CVF $30 \mathrm{~min}$ prior to occlusion of the left anterior descending coronary artery in dogs reduced necrosis and neutrophil infiltration into the myocardium (Maroko et al 1978). The complement proteins C3, C4, and C5 were deposited on infarcted tissue in a baboon model of AMI, and Laine et al showed that there was extensive deposition of $\mathrm{iC} 3 \mathrm{~b}$ in ruptured plaques, as compared to nonruptured plaques, from human coronary arteries in patients who had 
died from AMI (Pinckard et al 1980; McManus et al 1983; Laine et al 2002).

Patients with MI have increased post-infarction plasma levels of C5b-9 (Langlois and Gawryl 1988). Actually, levels of C3, C8, C9, and FB were all significantly increased in patients 6 and 12 hours after admission for MI (Halas et al 2005). C5b-9 was also found to be present in higher quantities in pathologic specimens of atherosclerotic plaques from patients with acute coronary syndrome (ACS) as compared to those with stable angina (Meuwissen et al 2006). Interestingly, the presence of C5b-9 in necrotic tissue was associated with the loss of CD59 in postmortem studies on patients who died from MI (Väkevä et al 1992).

Recently, several complement proteins have been studied as predictive markers in CAD leading to MI. For example, there was a substantial correlation between C3 levels and several cardiovascular risk factors, such as blood pressure, body mass index, and serum lipid levels (Engström et al 2007). C3 levels were shown to be a strong predictor of MI, especially in men, and $\mathrm{C} 3 \mathrm{a}$ levels were elevated in patients with unstable angina as compared to those with stable angina (Muscari et al 1995; Kostner et al 2006). Finally, C3 and C4 levels in patients admitted for AMI were significantly higher than in patients with stable angina or healthy controls, and the serum $\mathrm{C} 3 / \mathrm{C} 4$ ratio could possibly be used as a marker of subsequent cardiovascular events after a previous manifestation of ACS (Iltumur et al 2005; Palikhe et al 2007). Additionally, elevated C5a levels were shown to be associated with an increased risk of MI, PCIs, coronary artery bypass graft (CABG) surgery, carotid revascularization, stroke, or death in patients with advanced atherosclerosis (Speidl et al 2005).

C-reactive protein (CRP) interacts with the complement system. It was shown that CRP binds to damaged cardiomyocytes and activates the complement system (Kaplan and Volanakis 1974; Siegel et al 1974; Volanakis and Kaplan 1974; Volanakis 1982; Jiang et al 1992). The level of deposited CRP correlated with the extent of activation of the complement system in infarcted myocardial tissue as determined by measuring levels of complement proteins, CRP, and CRP-complement protein complexes (Nijmeijer et al 2003). In a rat model of MI, injection of human CRP increased the size of infarcted myocardial tissue. This effect of CRP was blocked by CVF-induced complement depletion even two hours after induction of MI (Griselli et al 1999).

The mainstay of treatment for MI is early revascularization through thrombolytic therapy, percutaneous coronary intervention $(\mathrm{PCI})$, or $\mathrm{CABG}$ surgery. However, revascularization carries with it the risk of ischemia-reperfusion injury, in which the complement system is activated. Reperfusion has been known to cause arrhythmias, microvascular dysfunction, and even cell death (Verma et al 2002). Reperfusion can also cause a condition known as myocardial stunning, which refers to diminished contractility of ischemic but still viable myocardium after full revascularization (Braunwald and Kloner 1982). The complement system has been shown to be involved in the acute inflammatory response associated with ischemia-reperfusion injury (Yasuda et al 1990; Eltzschig and Collard 2004). Activation of the complement system increases vascular permeability, activates endothelial and inflammatory cells, coagulates blood, and causes cell lysis.

\section{Therapy}

Several anticomplement therapies have been tried in different animal models of MI and ischemia-reperfusion, as well as in human clinical trials. One of the first anticomplement reagents used was the soluble form of complement receptor 1 (sCR1), a recombinant protein that comprises the extracellular part of the complement regulatory protein CR1. In an isolated rat model of ischemia-reperfusion injury, sCR1 was able to prevent post-ischemic myocardial contractile dysfunction and enhance coronary blood flow (Shandelya et al 1993). sCR1 modified with the addition of a myristoylated peptide sequence, creating a molecule known as Mirococept and giving sCR 1 the ability to bind to cell membranes, decreased infarct size, reduced serum troponin I, and resulted in a lower amount of complement deposition and myocardial apoptosis in a pig model of AMI (Banz et al 2007).

$\mathrm{C} 1-\mathrm{INH}$ has also been used with some success in different models of MI and ischemia-reperfusion. In a cat model of ischemia-reperfusion, $\mathrm{C} 1-\mathrm{INH}$ given just before reperfusion reduced infarct size by $65 \%$ (Buerke et al 1995). In a rat model of MI, C1-INH suppressed C3 mRNA expression and protein synthesis, while in cultured rat cardiomyocytes, C1-INH blocked deposition of C3 (Fu et al 2006b). In the same model of $\mathrm{MI}$ in rats, $\mathrm{C} 1$-INH protected against cardiomyocyte apoptosis, improved cardiac function, reduced infarct size, and decreased infiltration by neutrophils (Fu et al 2006a).

Treatment with $\mathrm{C} 1-\mathrm{INH}$ has also been studied in patients with MI. In one study, 22 patients received a loading dose of C1-INH followed by a continuous 48-hour infusion at least 6 hours after the onset of symptoms (de Zwaan et al 2002). In this small study, a C1-INH dose-dependent reduction in activation fragments of $\mathrm{C} 4$ was shown. In 13 of the 16 patients who received thrombolytic therapy and $\mathrm{C} 1-\mathrm{INH}$, 
the values of troponin $\mathrm{T}$ and creatine kinase-MB (CK-MB) were reduced by $36 \%$ and $57 \%$, respectively, as compared to 18 control patients who had AMI and did not receive C1-INH therapy.

The other component of the complement cascade that has been the target of anticomplement therapy in MI is C5. In a dog model of cardiac ischemia induced by ligation of the left circumflex artery, cardiac lymph obtained from the dogs several hours after reperfusion was able to activate neutrophils (Dreyer et al 1992). However, this effect was completely abolished when anti-C5a was added to the cardiac lymph. It was also shown that the monocyte chemotactic activity of cardiac lymph in the first few hours after reperfusion is almost completely due to C5a (Birdsall et al 1997). More directly, in a porcine model of ischemia-reperfusion, a recombinant human C5 antagonist, CGS 32359, was able to inhibit neutrophil activation and reduce infarct size (Riley et al 2000). Finally, in a rat model of ischemia-reperfusion, a monoclonal antibody against $\mathrm{C} 5$ reduced apoptosis, necrosis, and neutrophil infiltration (Vakeva et al 1998).

A large randomized, placebo-controlled phase II study of 960 patients, the COMplement inhibition in Myocardial infarction treated with Angioplasty (COMMA) trial, investigated the effect of anti-C5 therapy in AMI (Granger et al 2003). In this study, the anti-C5 agent pexelizumab (Alexion Pharmaceuticals, Cheshire, Connecticut, USA) was used. Patients with AMI who underwent primary PCI therapy were randomized to placebo, pexelizumab bolus given just before revascularization, and pexelizumab bolus plus subsequent infusion for 20 hours. There was no difference between the groups with respect to infarct size as determined by CK-MB area under the curve (AUC), but there was a significant benefit in 90-day mortality rate for the bolus plus infusion group $(1.8 \%)$ as compared to the placebo group (5.9\%).

In a substudy of the COMMA trial, there was a significant difference in the hemodynamic status of the groups treated with pexelizumab versus placebo after correcting for age, race, and MI location (Armstrong et al 2006). It was shown that this improved hemodynamic status was not due to infarct size, degree of ST-segment elevation, or extent of reperfusion. In another substudy of the COMMA trial, it was shown that higher CRP and interleukin-6 (IL-6) levels at baseline, 24 hours, and 72 hours were associated with increased death, and that elevated CRP, IL-6, and tumor necrosis factor- $\alpha$ levels were associated with more cardiogenic shock or death within 90 days of treatment (Théroux et al 2005). Despite similar serum levels of CRP and IL-6 at baseline, the pexelizumab-treated groups had significantly lower CRP and IL-6 levels at 24 hours, but by 72 hours, the values were similar between different groups.

The COMMA trial was the first part of a two-part phase II clinical trial called the Complement And ReDuction of INfarct size after Angioplasty or Lytics (CARDINAL) program. The results of the second part of the CARDINAL study, known as the COMPlement inhibition in myocardial infarction treated with thromboLYtics (COMPLY) trial, were also reported in 2003 (Mahaffey et al 2003). In this study, 943 patients who underwent fibrinolysis for ST-segment elevation MI (STEMI) were randomized similarly to the way patients were randomized in the COMMA trial. It was shown that pexelizumab lowered complement activity but had no effect on infarct size as measured by CK-MB AUC or on adverse clinical outcomes in the 90 days following treatment.

The follow-up to the CARDINAL program was a large, prospective, multicenter, randomized, double-blind, placebocontrolled phase III trial in which 5745 patients who had a STEMI treated with PCI were randomized to either placebo or treatment with pexelizumab as a bolus just before PCI and then as a 24-hour infusion after revascularization therapy (APEX AMI Investigators et al 2007). This trial showed no difference in 30-day all-cause mortality or in the 90-day composite of death, cardiogenic shock, or congestive heart failure.

\section{Coronary artery bypass graft surgery, ischemia-reperfusion injury, and cardiopulmonary bypass}

After revascularization with emergent CABG surgery in the setting of AMI, reperfusion can activate the complement system, similar to reperfusion with thrombolysis or angioplasty. Also, in cardiac surgery, use of cardiopulmonary bypass (CPB) exposes blood to nonself material in extracorporeal circuits, which in turn activate the alternative complement system. Thus, inhibition of complement activity may be beneficial in decreasing inflammation and tissue injury resulting from CABG surgery through two mechanisms, prevention of revascularization injury and reduced activation of the complement system associated with exposure of blood to extracorporeal circuits.

The effect of C1-INH was studied in 67 patients who underwent emergency CABG surgery for STEMI (Thielmann et al 2006). In this study, a bolus of C1-INH was given during, and another bolus given 6 hours after, surgery. It was shown that if $\mathrm{C} 1-\mathrm{INH}$ was given within 6 hours of the onset of symptoms, troponin I levels were reduced, but 
administration of C1-INH between 6 and 24 hours after the onset of symptoms failed to decrease troponin I levels. There was no difference between patients who received C1-INH and those who did not with respect to the length of hospital or intensive care unit (ICU) stays, post-operative complications, or in-hospital mortality, regardless of the initiation time of C1-INH infusion.

In another randomized, double-blind, placebo-controlled study, 80 patients with STEMI who underwent emergent $\mathrm{CABG}$ surgery were enrolled, with half receiving $\mathrm{C} 1-\mathrm{INH}$ and the other half receiving only a saline solution (Fattouch et al 2007). Patients received a bolus of C1-INH $10 \mathrm{~min}$ before reperfusion and then an intravenous infusion for 3 hours after surgery. Those receiving $\mathrm{C} 1$-INH showed a benefit in the amount of inotrope drugs required, intubation time, length of ICU stay, and various measures of cardiac function, such as mean arterial pressure, cardiac index, and stroke volume. The levels of troponin I after reperfusion were significantly lower in the C1-INH group as compared to the placebo group. However, the rate of early mortality was not significantly different between the two groups.

In one study of 564 patients, TP10 (a recombinant sCR1) or placebo was given to high-risk patients undergoing cardiac surgery requiring CPB (Lazar et al 2004). TP10 inhibited the complement system after 10-15 min of CPB, an inhibition which persisted until post-operative day (POD) 3 . The primary endpoint in this study was death, MI, prolonged intra-aortic balloon pump support, and prolonged intubation. The TP10 group showed a lower primary endpoint event rate by $30 \%$ only in male patients. In a follow-up study of 297 female patients randomized to treatment with TP10 or placebo, it was shown that TP10 suppressed complement activation but did not reduce the incidence of death or MI by 28 days after surgery (Lazar et al 2007). A possible reason for this lack of difference is that the number of adverse events in the control arm of this trial was quite low to begin with, at $17 \%$. Therefore, it became difficult to prove any statistical difference with only 297 patients. Thus, the study size combined with the low event rate in the placebo group together made it difficult to show any beneficial effect of TP10.

Heparin, as mentioned earlier, has long been known to possess anticomplement activity. In a pig model of ischemia-reperfusion, 40 pigs were studied: 10 pigs received $s C R 1,10$ underwent surgery with heparin-bonded CPB (HB-CPB) circuits, 10 received sCR1 and underwent surgery with HB-CPB circuits, and 10 neither received sCR1 nor underwent surgery with HB-CPB circuits (Lazar et al 1999). As expected, sCR1 combined with the use of
HB-CPB circuits led to less myocardial tissue acidosis, better recovery of wall motion, less pulmonary edema, and smaller infarct size.

In a human trial, the effect of heparin on complement activation was studied in 151 patients undergoing cardiac surgery. Heparin coating of CBP circuits reduced complement activation, especially C5b-9 formation, but did not reduce the release of the neutrophil granule enzymes myeloperoxidase and lactoferrin (Fosse et al 1997).

Pexelizumab has also been studied in patients undergoing cardiac surgery requiring $\mathrm{CPB}$. One of the first studies conducted was a prospective, open-label, randomized phase I study in 17 patients who underwent primary, nonemergent CABG surgery with CPB. In the first phase of the study, patients were randomized to receive escalating doses of h5G1.1-scFv (not yet known as pexelizumab) (Fitch et al 1999). In another part of the study, 18 patients were randomized into 3 groups and received placebo or one of two different doses of h5G1.1-scFv. It was shown that leukocyte activation, determined by expression of $\mathrm{CD} 11 \mathrm{~b}$, was reduced in patients receiving the higher doses of h5G1.1-scFv. In those patients receiving the highest dose of $\mathrm{h} 5 \mathrm{G} 1.1-\mathrm{scFv}(2 \mathrm{mg} / \mathrm{kg})$, a $40 \%$ reduction in $\mathrm{CK}-\mathrm{MB}$ was observed. In addition, in patients treated with the highest dose of h5G1.1-scFv, there was an $80 \%$ reduction in new cognitive deficits as determined by sequential mini-mental status exams.

In a follow-up to this study, a randomized, double-blind, placebo-controlled multicenter phase II trial in patients who underwent nonemergent $\mathrm{CABG}$ surgery with or without concomitant valve surgery, participants were randomized into three groups, those receiving placebo, those receiving a pexelizumab bolus, and those receiving a pexelizumab bolus and subsequent infusion (Shernan et al 2004). It was shown that giving pexelizumab as a bolus plus infusion reduced the composite of death or $\mathrm{MI}$ in patients undergoing $\mathrm{CABG}$ surgery only without valve surgery on POD 4 and POD 30. There was, however, no difference in the primary endpoint, namely the composite of death, new MI, left ventricular dysfunction, or new neurological events, between the two groups overall.

This phase II trial was further analyzed from the neurological perspective in a follow-up substudy (Mathew et al 2004). Neurological and neurocognitive functions were assessed on POD 4 and POD 30 in patients enrolled in the substudy. Pexelizumab had no effect on overall cognition on either day. The only difference was in visuo-spatial function, which was significantly better in the treated group as compared to the placebo group on POD 4 and POD 30. 
This phase II trial was followed up with a larger phase III, randomized, double-blind, placebo-controlled, multicenter study of 3099 patients undergoing nonemergent CABG surgery with or without valve surgery (Verrier et al 2004). In this study, termed the Pexelizumab for Reduction in Infarction and MOrtality in Coronary Artery Bypass Graft surgery (PRIMO-CABG) trial, patients were randomized into two groups, one receiving an intravenous bolus of pexelizumab plus a subsequent 24 -hour infusion and the other receiving placebo. The primary endpoint in this trial was the composite of death or MI within 30 days of surgery. This large, extensive study did not show any significant difference between the two groups with regard to the incidence of death or MI at 30 days, with the event rate being 9.8\% (134/1373) in patients who received pexelizumab and $11.8 \%(161 / 1359)$ in patients who received placebo $(\mathrm{p}=0.07)$.

In a substudy of the PRIMO-CABG trial, it was shown that pexelizumab reduced the incidence of death or MI by POD 30 by $28 \%$ in patients with two or more risk factors, including DM, prior CABG surgery, urgent intervention, female sex, history of a neurological event, CHF, two or more previous MIs, or a recent MI (Haverich et al 2006). In separate follow-up analysis, a subgroup of patients with aortic cross-clamp times $>90$ min showed reduced perioperative myocardial injury (Smith et al 2006). Of this specific subset of patients, those with two or more serious cardiovascular risk factors had a reduced incidence of death or MI through POD 30 and a significantly reduced incidence of mortality 180 days after surgery.

In one final substudy analysis of patients in the PRIMO-CABG trial, pexelizumab reduced mortality at 180 days in patients who underwent aortic valve replacement (AVR) at the time of CABG surgery (Carrier et al 2006). However, both mortality and the incidence of MI at 30 days were not significantly different between those who had an AVR with their CABG surgery and those who did not.

In a broad meta-analysis of the four large trials with pexelizumab described above (COMMA, COMPLY, Phase II CABG study, and PRIMO-CABG), using data from 5916 patients who either had an AMI treated with PCI or thrombolytic therapy or who underwent CABG surgery, it was shown that pexelizumab reduced 30-day mortality when given as a bolus followed by subsequent infusion (Mahaffey et al 2006).

The angioplasty, thrombolytic, and CABG surgery trials involving anticomplement therapy did not provide as much benefit to patients as had been hoped for. We can only speculate about why the in vitro and animal studies did not translate to successful therapeutic results in human trials; however, advances in the complement science and in understanding of thrombotic disorders will provide the real answers.

\section{Future directions}

In addition to the clinical applications described in the previous section, there are two other main clinical conditions with potential therapeutic roles for complement regulatory proteins.

\section{Sepsis}

There are several studies reporting an increase in complement activation products (C5a, C3a, C5b-9) in animal models of sepsis, as well as in patients with sepsis and multiorgan system failure (Ward 2008). For example, in the setting of experimental sepsis in mice or rats induced by cecal ligation and puncture, there is an upregulation of $\mathrm{C} 5 \mathrm{a}$ receptor (C5aR) in solid organs and on the surface of neutrophils (Riedemann et al 2002; Ward 2008). Despite an increase in the concentration of $\mathrm{C} 5 \mathrm{a}$, the normal functions of neutrophils, including chemotaxis, phagocytosis, and oxidative burst, are impaired during sepsis (Huber-Lang et al 2002b). These abnormalities in neutrophil function are probably due to a paralysis of C5a signaling (Ward 2008). Using anti-C5a antibody or anti-C5aR cyclic peptide can reverse neutrophil paralysis and, more importantly, can increase survival in animals with severe sepsis (Huber-Lang et al 2001, 2002a). To date, no trials using anti-C5a antibody or anti-C5aR agents have been performed in patients with sepsis.

\section{Age-related macular degeneration}

Age-related macular degeneration (AMD) is a leading cause of blindness among older individuals in developed countries. In 1998, a genome-wide screening study in a family with AMD identified the long arm of chromosome 1 (1q25-q31) as the locus for the responsible gene (Klein et al 1998). In 2005, three independent studies using different methods identified an association between a polymorphism in factor $\mathrm{H}$ (Tyr402His) and AMD in the general population (Edwards et al 2005; Haines et al 2005; Klein et al 2005). Later on, associations between AMD and additional polymorphisms in the factor $\mathrm{H}$ gene, as well as polymorphisms in other complement proteins, were detected (Gold et al 2006; Hughes et al 2006; Li et al 2006; Maller et al 2006; Dinu et al 2007). Functional and anatomical studies conducted on factor $\mathrm{H}$-deficient mice revealed a significant reduction in visual acuity and abnormalities in electroretinography of factor $\mathrm{H}$-deficient mice as compared to 
control mice (Coffey et al 2007). These functional abnormalities were associated with complement deposition and altered retinal structure. Studies using factor $\mathrm{H}$ purified from serum and recombinant factor $\mathrm{H}$ showed decreased binding of the $402 \mathrm{His}$ variant of factor $\mathrm{H}$ to $\mathrm{CRP}$ and heparin as compared to the wild-type 402Tyr variant (Clark et al 2006; Laine et al 2007). Despite the presence of strong data linking polymorphisms in factor $\mathrm{H}$ to retinal damage in AMD, further animal and human studies are required before this information may be applied to clinical use.

\section{Conclusion}

The field of anticomplement therapy is a rapidly-evolving one and has much potential for future benefit in clinical medicine. It will arguably have the most impact in the treatment of $\mathrm{PNH}$, for which anticomplement therapy has been shown to be a highly effective treatment. As for the use of anticomplement therapy in the treatment of CAD and its complications, initial studies appeared promising, but larger, more extensive studies turned out to be more disappointing than had been desired. However, since the complement system is a complex, multifaceted system, there are potentially many more therapeutic targets that may be exploited in the future for the treatment of CAD, glomerulonephritis, sepsis, AMD, and many other diseases.

\section{Disclosure}

The authors report no conflicts of interest in this work.

\section{References}

Abrera-Abeleda MA, Xu Y, Pickering MC, et al. 2007. Mesangial immune complex glomerulonephritis due to complement factor D deficiency. Kidney Int, 71:1142-7.

Almeda S, Rosenberg RD, Bing DH. 1983. The binding properties of human complement component C1q. Interaction with mucopolysaccharides. $J$ Biol Chem, 258:785-91.

APEX AMI Investigators, Armstrong PW, Granger CB, et al. 2007. Pexelizumab for acute ST-elevation myocardial infarction in patients undergoing primary percutaneous coronary intervention: a randomized controlled trial. JAMA, 297:43-51.

Appel G, Nachman P, Hogas S, et al. 2002. Eculizumab (C5a complement inhibitor) in the treatment of idiopathic membranous nephropathy [abstract]. J Am Soc Nephro, 13:668-1857.

Armstrong PW, Mahaffey KW, Chang WC, et al. 2006. Concerning the mechanism of pexelizumab's benefit in acute myocardial infarction. Am Heart J, 151:787-90.

Baker PJ, Lint TF, McLeod BC, et al. 1975. Studies on the inhibition of C56-induced lysis (reactive lysis). VI. Modulation of C56-induced lysis polyanions and polycations. J Immunol, 114:554-8.

Banz Y, Hess OM, Robson SC, et al. 2007. Attenuation of myocardial reperfusion injury in pigs by Mirococept, a membrane-targeted complement inhibitor derived from human CR1. Cardiovasc Res, 76:482-93.

Bao L, Haas M, Minto AW, et al. 2007. Decay-accelerating factor but not CD59 limits experimental immune-complex glomerulonephritis. Lab Invest, 87:357-64.
Bao L, Osawe I, Puri T, et al. 2005. C5a promotes development of experimental lupus nephritis which can be blocked with a specific receptor antagonist. Eur J Immunol, 35:2496-506.

Berger SP, Daha MR. 2007. Complement in glomerular injury. Semin Immunopathol, 29:375-84.

Berger SP, Roos A, Daha MR. 2005. Complement and the kidney: what the nephrologist needs to know in 2006? Nephrol Dial Transplant, 20:2613-9.

Bessler M, Mason PJ, Hillmen P, et al. 1994. Paroxysmal nocturnal hemoglobinuria $(\mathrm{PNH})$ is caused by somatic mutation in the PIG-A gene. EMBO J, 13:110-7.

Birdsall HH, Green DM, Trial J, et al. 1997. Complement C5a, TGF-beta 1, and MCP-1, in sequence, induce migration of monocytes into ischemic canine myocardium within the first one to five hours after reperfusion. Circulation, 95:684-92.

Braunwald E, Kloner RA. 1982. The stunned myocardium: prolonged, post-ischemic ventricular dysfunction. Circulation, 66:1146-9.

Brown KM, Sacks SH, Sheerin NS. 2007. Mechanisms of disease: the complement system in renal injury - new ways of looking at an old foe. Nat Clin Pract Nephrol, 3:277-86.

Buerke M, Murohara T, Lefer AM. 1995. Cardioprotective effects of a C1 esterase inhibitor in myocardial ischemia and reperfusion. Circulation, 91:393-402.

Capuano V, D'Arminio T, La Sala G, et al. 2006. The third component of the complement (C3) is a marker of the risk of atherogenesis. Eur $J$ Cardiovasc Prev Rehabil, 13:658-60.

Carrier M, Menasche P, Levy JH, et al. 2006. Inhibition of complement activation by pexelizumab reduces death in patients undergoing combined aortic valve replacement and coronary artery bypass surgery. J Thorac Cardiovasc Surg, 131:352-6.

Christiansen D, Milland J, Thorley BR, et al. 1996. Engineering of recombinant soluble CD46: an inhibitor of complement activation. Immunol, 87:348-54.

Clark SJ, Higman VA, Mulloy B, et al. 2006. His-384 allotypic variant of factor $\mathrm{H}$ associated with age-related macular degeneration has different heparin binding properties from the non-disease-associated form. $J$ Biol Chem, 281:24713-20.

Cochrane CG, Muller-Eberhard HJ, Aikin BS. 1970. Depletion of plasma complement in vivo by a protein of cobra venom: its effect on various immunologic reactions. J Immunol, 105:55-69.

Coffey PJ, Gias C, McDermott CJ, et al. 2007. Complement factor $\mathrm{H}$ deficiency in aged mice causes retinal abnormalities and visual dysfunction. Proc Natl Acad Sci U S A, 104:16651-6.

Cooper NR. 1973. Formation and function of a complex of the $C 3$ proactivator with a protein from cobra venom. $J$ Exp Med, 137:451-60.

Couser WG, Johnson RJ, Young BA, et al. 1995. The effects of soluble recombinant complement receptor 1 on complement-mediated experimental glomerulonephritis. J Am Soc Nephrol, 5:1888-94.

Cummings KL, Waggoner SN, Tacke R, et al. 2007. Role of complement in immune regulation and its exploitation by virus. Viral Immunol, 20:505-24.

Daha MR, Fearon DT, Austen KF. 1976. C3 nephritic factor (C3NeF): stabilization of fluid phase and cell-bound alternative pathway convertase. J Immunol, 116:1-7.

de Zwaan C, Kleine AH, Diris JH, et al. 2002. Continuous 48-h C1-inhibitor treatment, following reperfusion therapy, in patients with acute myocardial infarction. Eur Heart J, 23:1670-7.

Dinu V, Miller PL, Zhao H. 2007. Evidence for association between multiple complement pathway genes and AMD. Genet Epidemiol, 31:224-37.

Dreyer WJ, Michael LH, Nguyen T, et al. 1992. Kinetics of C5a release in cardiac lymph of dogs experiencing coronary artery ischemia-reperfusion injury. Circ Res, 71:1518-24.

Edwards AO, Ritter R 3rd, Abel KJ, et al. 2005. Complement factor $\mathrm{H}$ polymorphism and age-related macular degeneration. Science, 308:421-4.

Eltzschig HK, Collard CD. 2004. Vascular ischaemia and reperfusion injury. Br Med Bull, 70:71-86. 
Engström G, Hedblad B, Janzon L, et al. 2007. Complement C3 and C4 in plasma and incidence of myocardial infarction and stroke: a populationbased cohort study. Eur J Cardiovasc Prev Rehabil, 14:392-7.

Fattouch K, Bianco G, Speziale G, et al. 2007. Beneficial effects of C1 esterase inhibitor in ST-elevation myocardial infarction in patient who underwent surgical reperfusion: a randomised double-blind study. Eur J Cardiothorac Surg, 32:326-32.

Fitch JC, Rollins S, Matis L, et al. 1999. Pharmacology and biological efficacy of a recombinant, humanized, single-chain antibody C5 complement inhibitor in patients undergoing coronary artery bypass graft surgery with cardiopulmonary bypass. Circulation, 100:2499-506.

Flexner S, Noguchi H. 1903. Snake venom in relation to hemolysis, bacteriolysis and toxicity. $J$ Exp Med, 6:277-301.

Fosse E, Thelin S, Svennevig JL, et al. 1997. Duraflo II coating of cardiopulmonary bypass circuits reduces complement activation, but does not affect the release of granulocyte enzymes: a European multicentre study. Eur J Cardiothorac Surg, 11:320-7.

Fujii S, Hitomi Y. 1981. New synthetic inhibitors of C1r, C1 esterase, thrombin, plasmin, kallikrein, and trypsin. Biochim Biophys Acta, 661:342-45.

$\mathrm{Fu}$ J, Lin G, Wu Z, et al. 2006a. Anti-apoptotic role for C1 inhibitor in ischemia/reperfusion-induced myocardial cell injury. Biochem Biophys Res Commun, 349:504-12.

Fu J, Lin G, Zeng B, et al. 2006b. Anti-ischemia/reperfusion of C1 inhibitor in myocardial cell injury via regulation of local myocardial $\mathrm{C} 3$ activity. Biochem Biophys Res Commun, 350:162-8.

Gewurz H, Clark DS, Cooper MD, et al. 1967. Effect of cobra venom-induced inhibition of complement activity on allograft and xenograft rejection reactions. Transplantation, 5:1296-303.

Gold B, Merriam JE, Zernant J, et al. 2006. Variation in factor B (BF) and complement component $2(\mathrm{C} 2)$ genes is associated with age-related macular degeneration. Nat Genet, 38:458-62.

Granger CB, Mahaffey KW, Weaver WD, et al. 2003. Pexelizumab, an anti-C5 complement antibody, as adjunctive therapy to primary percutaneous coronary intervention in acute myocardial infarction: the COMplement Inhibition in Myocardial Infarction treated with Angioplasty (COMMA) trial. Circulation, 108:1184-90.

Griselli M, Herbert J, Hutchinson WL, et al. 1999. C-reactive protein and complement are important mediators of tissue damage in acute myocardial infarction. J Exp Med, 190:1733-40.

Halas YA, Rahal E, Abdelnoor AM, et al. 2005. Serum C-reactive protein and complement proteins in patients with acute myocardial infarction. Immunopharmacol Immunotoxicol, 27:405-16.

Haines JL, Hauser MA, Schmidt S, et al. 2005. Complement factor H variant increases the risk of age-related macular degeneration. Science, 308:419-21.

Hansson GK, Holm J, Kral IG. 1984. Accumulation of IgG and complement factor $\mathrm{C} 3$ in human arterial endothelium and atherosclerotic lesions. Acta Pathol Microbiol Immunol Scand A, 92:429-35.

Harris CL, Williams AS, Linton SM, et al. 2002. Coupling complement regulators to immunoglobulin domains generates effective anti-complement reagents with extended half-life in vivo. Clin Exp Immunol, 129:198-207.

Haverich A, Shernan SK, Levy JH, et al. 2006. Pexelizumab reduces death and myocardial infarction in higher risk cardiac surgical patients. Ann Thorac Surg, 82:486-92.

Higgins PJ, Ko JL, Lobell R, et al. 1997. A soluble chimeric complement inhibitory protein that possesses both decay-accelerating and factor I co-factor activities. J Immunol, 158:2872-81.

Hill A, Hillmen P, Richards SJ, et al. 2005a. Sustained response and long-term safety of eculizumab in paroxysmal nocturnal hemoglobinuria. Blood, 106:2559-65.

Hill A, Richards SJ, Hillmen P. 2007. Recent developments in the understanding and management of paroxysmal nocturnal hemoglobinuria. Br J Haematol, 137:181-92.

Hill A, Ridley SH, Esser D, et al. 2006. Protection of erythrocytes from human complement-mediated lysis by membrane-targeted recombinan soluble CD59: a new approach to PNH therapy. Blood, 107:2131-7.
Hill A, Rother RP, Hillmen P. 2005b. Improvement in the symptoms of smooth muscle dystonia during eculizumab therapy in paroxysmal nocturnal hemoglobinuria. Haematologica, 90:ECR40.

Hillmen P, Hall C, Marsh JC, et al. 2004. Effect of eculizumab on hemolysis and transfusion requirements in patients with paroxysmal nocturnal hemoglobinuria. N Engl J Med, 350:552-9.

Hillmen P, Lewis SM, Bessler M, et al. 1995. Natural history of paroxysmal nocturnal hemoglobinuria. $N$ Engl J Med, 333:1253-8.

Hillmen P, Muus P, Duhrsen U, et al. 2007. Effect of the complement inhibitor eculizumab on thromboembolism in patients with paroxysmal nocturnal hemoglobinuria. Blood, 110:4123-8.

Hillmen P, Young NS, Schubert J, et al. 2006. The complement inhibitor eculizumab in paroxysmal nocturnal hemoglobinuria. $N$ Engl $\mathrm{J}$ Med, 355:1233-43.

Hitomi Y, Fujii S. 1982. Inhibition of various immunological reactions in vivo by a new synthetic complement inhibitor. Int Arch Allergy Appl Immunol, 69:262-7.

Hollander W, Colombo MA, Kramsch DM, et al. 1979. Soluble proteins in the human atherosclerotic plaque. With spectral reference to immunoglobulins, $\mathrm{C} 3$ complement component, alpha 1 antitrypsin and alpha 2 macroglobulin. Atherosclerosis, 34:391-405.

Huber-Lang MS, Riedemann NC, Sarma JV, et al. 2002a. Protection of innate immunity by $\mathrm{C} 5 \mathrm{aR}$ antagonist in septic mice. FASEB J, 16:1567-74.

Huber-Lang MS, Sarma JV, McGuire SR, et al. 2001. Protective effects of anti-C5a peptide antibodies in experimental sepsis. FASEB $J$, 15:568-70.

Huber-Lang MS, Younkin EM, Sarma JV, et al. 2002b. Complementinduced impairment of innate immunity during sepsis. J Immunol, 169:3223-31

Hughes AE, Orr N, Esfandiary H, et al. 2006. A common CFH haplotype, with deletion of CFHR1 and CFHR3, is associated with lower risk of age-related macular degeneration. Nat Genet, 38:1173-7.

Hughes-Jones NC, Gardner B. 1978. The reaction between the complement subcomponent $\mathrm{C} 1 \mathrm{q}, \mathrm{IgG}$ complexes and polyionic molecules. Immunol, 34:459-63.

Huugen D, van Esch A, Xiao H, et al. 2007. Inhibition of complement factor $\mathrm{C} 5$ protects against anti-myeloperoxidase antibody-mediated glomerulonephritis in mice. Kidney Int, 71:646-54.

Iltumur K, Karabulut A, Toprak G, et al. 2005. Complement activation in acute coronary syndromes. APMIS, 113:167-74.

Inagi R, Miyata T, Maeda K, et al. 1991. FUT-175 as a potent inhibitor of $\mathrm{C} 5 / \mathrm{C} 3$ convertase activity for production of $\mathrm{C} 5 \mathrm{a}$ and $\mathrm{C} 3 \mathrm{a}$. Immunol Lett, 27:49-52.

Janeway CA, Travers P, Walport M, et al. 1999. The humoral immune response. Immunobiology. The immune system in health and disease. 4th ed. New York: Elsevier Science Ltd/Garland. p. 339-58.

Javaid B, Quigg RJ. 2005. Treatment of glomerulonephritis: will we ever have options other than steroids and cytotoxics? Kidney Int, 67:1692-703.

Jiang H, Robey FA, Gewurz H. 1992. Localization of sites through which C-reactive protein binds and activates complement to residues 14-26 and 76-92 of the human C1q A chain. J Exp Med, 175:1373-9.

Kaplan MH, Volanakis JE. 1974. Interaction of C-reactive protein complexes with the complement system. I. Consumption of human complement associated with the reaction of $\mathrm{C}$-reactive protein with pneumococcal C-polysaccharide and with the choline phosphatides, lecithin, and sphingomyelin. J Immunol, 112:2135-47.

Klein ML, Schultz DW, Edwards A, et al. 1998. Age-related macular degeneration. Clinical features in a large family and linkage to chromosome 1q. Arch Ophthalmol, 116:1082-8.

Klein RJ, Zeiss C, Chew EY, et al. 2005. Complement factor H polymorphism in age-related macular degeneration. Science, 308:385-9.

Kostner KM, Fahti RB, Case C, et al. 2006. Inflammation, complement activation and endothelial function in stable and unstable coronary artery disease. Clin Chim Acta, 365:129-34. 
Kroshus TJ, Rollins SA, Dalmasso AP, et al. 1995. Complement inhibition with an anti-C5 monoclonal antibody prevents acute cardiac tissue injury in an ex vivo model of pig-to-human xenotransplantation. Transplantation, 60:1194-202.

Kroshus TJ, Salerno CT, Yeh CG, et al. 2000. A recombinant soluble chimeric complement inhibitor composed of human CD46 and CD55 reduces acute cardiac tissue injury in models of pig-to-human heart transplantation. Transplantation, 69:2282-9.

Laine M, Jarva H, Seitsonen S, et al. 2007. Y402H polymorphism of complement factor $\mathrm{H}$ affects binding affinity to $\mathrm{C}$-reactive protein. J Immunol, 178:3831-6.

Laine P, Pentikäinen MO, Würzner R, et al. 2002. Evidence for complement activation in ruptured coronary plaques in acute myocardial infarction. Am J Cardiol, 90:404-8.

Langlois PF, Gawryl MS. 1988. Detection of the terminal complement complex in patient plasma following acute myocardial infarction. Atherosclerosis, 70:95-105.

Lazar HL, Bao Y, Gaudiani J, et al. 1999. Total complement inhibition: an effective strategy to limit ischemic injury during coronary revascularization on cardiopulmonary bypass. Circulation, $100: 1438-42$

Lazar HL, Bokesch PM, van Lenta F, et al. 2004. Soluble human complement receptor 1 limits ischemic damage and cardiac surgery patients at high risk requiring cardiopulmonary bypass. Circulation, 110(11 Suppl 1):II274-9.

Lazar HL, Keilani T, Fitzgerald CA, et al. 2007. Beneficial effects of complement inhibition with soluble complement receptor 1 (TP10) during cardiac surgery: is there a gender difference? Circulation, 116(Suppl 11):183-8.

Li M, Atmaca-Sonmez P, Othman M, et al. 2006. CFH haplotypes without the $\mathrm{Y} 402 \mathrm{H}$ coding variant show strong association with susceptibility to age-related macular degeneration. Nat Genet, 38:1049-54.

Lin F, Salant DJ, Meyerson H, et al. 2004. Respective roles of decay-accelerating factor and CD59 in circumventing glomerular injury in acute nephrotoxic serum nephritis. $J$ Immunol, 172:2636-42.

Mahaffey KW, Granger CB, Nicolau JC, et al. 2003. Effect of pexelizumab, an anti-C5 complement antibody, as adjunctive therapy to fibrinolysis in acute myocardial infarction: the COMPlement inhibition in myocardial infarction treated with thromboLYtics (COMPLY) trial. Circulation, 108:1176-83

Mahaffey KW, Van de Werf F, Shernan SK, et al. 2006. Effect of pexelizumab on mortality in patients with acute myocardial infarction or undergoing coronary artery bypass surgery: a systematic overview. Am Heart J, 152:291-6.

Maillard JL; Zarco RM. 1968. Decomplementization by a factor extracted from cobra venom. Effect on several immune reactions of the guinea pig and rat. Ann Inst Pasteur Paris, 114:756-74.

Maller J, George S, Purcell S, et al. 2006. Common variation in three genes, including a noncoding variant in $\mathrm{CFH}$, strongly influences risk of age-related macular degeneration. Nat Genet, 38:1055-9.

Maroko PR, Carpenter CB, Chiariello M, et al. 1978. Reduction by cobra venom factor of myocardial necrosis after coronary artery occlusion. J Clin Invest, 61:661-70.

Mathew JP, Shernan SK, White WD, et al. 2004. Preliminary report of the effects of complement suppression with pexelizumab on neurocognitive decline after coronary artery bypass graft surgery. Stroke, 35:2335-9.

McManus LM, Kolb WP, Crawford MH, et al. 1983. Complement localization in ischemic baboon myocardium. Laboratory Invest, 48:436-47.

Meuwissen M, van der Wal AC, Niessen HW, et al. 2006. Colocalisation of intraplaque $\mathrm{C}$ reactive protein, complement oxidised low density lipoprotein, and macrophages in stable and unstable angina and acute myocardial infarction. J Clin Pathol, 59:196-201.

Mitchell DA, Pickering MC, Warren J, et al. 2002. C1q deficiency and autoimmunity: the effects of genetic background on disease expression. J Immunol, 168:2538-43.

Moran P, Beasley H, Gorrell A, et al. 1992. Human recombinant soluble decay accelerating factor inhibits complement activation in vitro and in vivo. J Immunol, 149:1736-43.
Morgan BP, Harris CL. 2003. Complement therapeutics; history and current progress. Mol Immunol, 40:159-70.

Moroni G, Trendelenburg M, Del Papa N, et al. 2001. Anti-Clq antibodies may help in diagnosing a renal flare in lupus nephritis. Am J Kidney Dis, 37:490-8.

Muller-Eberhard HJ, Fjellstrom KE. 1971. Isolation of the anticomplementary protein from cobra venom and its mode of action on C3. J Immunol, 107:1666-72.

Muscari A, Bozzoli C, Puddu GM, et al. 1995. Association of serum C3 levels with the risk of myocardial infarction. Am J Med, 98:357-64.

Muscari A, Massarelli G, Bastagli L, et al. 2000. Relationship of serum $\mathrm{C} 3$ to fasting insulin, risk factors, and previous ischaemic events in middle-aged men. Eur Heart J, 21:1081-90.

Myllymäki J, Saha H, Pasternack A, et al. 2006. High serum C3 predicts poor outcome in IgM nephropathy. Nephron Clin Pract, 102:c122-7.

Nijmeijer R, Lagrand WK, Lubbers YT, et al. 2003. C-reactive protein activates complement in infarcted human myocardium. Am J Pathol, 163:269-75

Oksjoki R, Kovanen PT, Meri S, et al. 2007. Function and regulation of the complement system in cardiovascular diseases. Front Biosci, 12:4696-708

Palikhe A, Sinisalo J, Seppänen M, et al. 2007. Serum complement C3/C4 ratio, a novel marker for recurrent cardiovascular events. Am J Cardiol, 99:890-5.

Phillips GB. 1970. Studies on a hemolytic factor of cobra venom requiring a heat-labile serum factor. Biochim Biophys Acta, 201:364-74.

Pickering MC, Cook HT, Warren J, et al. 2002. Uncontrolled C3 activation causes membranoproliferative glomerulonephritis in mice deficient in complement factor H. Nat Genet, 31:424-8.

Pickering MC, Warren J, Rose KL, et al. 2006. Prevention of C5 activation ameliorates spontaneous and experimental glomerulonephritis in factor H-deficient mice. Proc Natl Acad Sci U S A, 103:9649-54.

Pinckard RN, O'Rourke RA, Crawford MH, et al. 1980. Complement localization and mediation of ischemic injury in baboon myocardium. $J$ Clin Invest, 66:1050-6.

Pugsley MK. 2001. Etanercept. Immunex. Curr Opin Investig Drugs, 2:1725-31.

Qin X, Gao B. 2006. The complement system in liver diseases. Cell Mol Immunol, 3:333-40.

Ravirajan CT, Wang Y, Matis LA, et al. 2004. Effect of neutralizing antibodies to IL-10 and C 5 on the renal damage caused by a pathogenic human anti-dsDNA antibody. Rheumatology (Oxford), 43:442-7.

Richards SJ, Hill A, Hillmen P. 2007. Recent advances in the diagnosis, monitoring, and management of patients with paroxysmal nocturnal hemoglobinuria. Cytometry B Clin Cytom, 72:291-8.

Riedemann NC, Guo RF, Neff TA, et al. 2002. Increased C5a receptor expression in sepsis. $J$ Clin Invest, 110:101-8.

Riley RD, Sato H, Zhao ZQ, et al. 2000. Recombinant human complement C5 a receptor antagonist reduces infarct size after surgical revascularization. J Thorac Cardiovasc Surg, 120:350-8.

Roos A, Nauta AJ, Broers D, et al. 2001. Specific inhibition of the classical complement pathway by C1q-binding peptides. J Immunol, 167:7052-9.

Sahu A, Kay BK, Lambris JD. 1996. Inhibition of human complement by a C3-binding peptide isolated from a phage-displayed random peptide library. J Immunol, 157:884-91.

Schwertz R, Rother U, Anders D, et al. 2001. Complement analysis in children with idiopathic membranoproliferative glomerulonephritis: a long-term follow-up. Pediatr Allergy Immunol, 12:166-72.

Seelen MA, Trouw LA, Daha MR. 2003. Diagnostic and prognostic significance of anti-C1q antibodies in systemic lupus erythematosus. Curr Opin Nephrol Hypertens, 12:619-24.

Seifert PS, Hansson GK. 1989a. Complement receptors and regulatory proteins in human atherosclerotic lesions. Arteriosclerosis, 9:802-11.

Seifert PS, Hansson GK. 1989b. Decay accelerating factor is expressed on vascular smooth muscle cells in human atherosclerotic lesions. J Clin Invest, 84:597-604. 
Seifert PS, Roth I, Schmid W, et al. 1992. CD59, (homologous restriction factor 20), a plasma membrane protein that protects against complement C5b-9 attack in human atherosclerotic lesions. Atherosclerosis, 96:135-45.

Shandelya SM, Kuppusamy P, Herskowitz A, et al. 1993. Soluble complement receptor type 1 inhibits the complement pathway and prevents contractile failure in the postischemic heart. Evidence that complement activation is required for neutrophil-mediated reperfusion injury. Circulation, 88:2812-26.

Shernan SK, Fitch JC, Nussmeier NA, et al. 2004. Impact of pexelizumab, an anti-C5 complement antibody, on total mortality and adverse cardiovascular outcomes in cardiac surgical patients undergoing cardiopulmonary bypass. Ann Thorac Surg, 77:942-9.

Siegel J, Rent R, Gewurz H. 1974. Interactions of C-reactive protein with the complement system. I. Protamine-induced consumption of complement in acute phase sera. $J$ Exp Med, 140:631-47.

Smith PK, Carrier M, Chen JC, et al. 2006. Effect of pexelizumab in coronary artery bypass graft surgery with extended aortic cross-clamp time. Ann Thorac Surg, 82:781-8.

Socie G, Mary JY, de Gramont A, et al. 1996. Paroxysmal nocturnal hemoglobinuria: Long-term follow-up and prognostic factors. French society for haematology. Lancet, 348:573-7.

Speidl WS, Exner M, Amighi J, et al. 2005. Complement component C5a predicts future cardiovascular events in patients with advanced atherosclerosis. Eur Heart J, 26:2294-9.

Spitzer D, Unsinger J, Bessler M, et al. 2004. ScFv-mediated in vivo targeting of DAF to erythrocytes inhibits lysis by complement. Mol Immunol, 40:911-9.

Takeda J, Miyata T, Kawagoe K, et al. 1993. Deficiency of the GPI anchor caused by a somatic mutation of the PIG-A gene in paroxysmal nocturnal hemoglobinuria. Cell, 73:703-11.

Théroux P, Armstrong PW, Mahaffey KW, et al. 2005. Prognostic significance of blood markers of inflammation in patients ST-segment elevation myocardial infarction undergoing primary angioplasty and effects of pexelizumab, a C5 inhibitor: a substudy of the COMMA trial. Eur Heart J, 26:1964-70.

Thielmann M, Marggraf G, Neuhauser M, et al. 2006. Administration of C1esterase inhibitor during emergency coronary artery bypass surgery in acute ST-elevation myocardial infarction. Eur J Cardiothorac Surg, 30:285-93.

Thomas TC, Rollins SA, Rother RP, et al. 1996. Inhibition of complement activity by humanized anti-C5 antibody and single-chain Fv. Mol Immunol, 33:1389-401.

Trendelenburg M, Lopez-Trascasa M, Potlukova E, et al. 2006. High prevalence of anti-C1q antibodies in biopsy-proven active lupus nephritis. Nephrol Dial Transplant, 21:3115-21.

Turnberg D, Botto M, Warren J, et al. 2003. CD59a deficiency exacerbates accelerated nephrotoxic nephritis in mice. $J$ Am Soc Nephrol, 14:2271-9.

Väkevä A, Laurila P, Meri S. 1992. Loss of expression of protectin (CD59) is associated with complement membrane attack complex deposition in myocardial infarction. Laboratory Invest, 67:608-16.
Vakeva AP, Agah A, Rollins SA, et al. 1998. Myocardial infarction and apoptosis after myocardial ischemia and reperfusion: role of the terminal complement components and inhibition by anti-C5 therapy. Circulation, 97:2259-67.

Verma S, Fedak PW, Weisel RD, et al. 2002. Fundamentals of reperfusion injury for the clinical cardiologist. Circulation, 105:2332-6.

Verrier ED, Shernan SK, Taylor KM, et al. 2004. Terminal complement blockade with pexelizumab during coronary artery bypass graft surgery requiring cardiopulmonary bypass: a randomized trial. JAMA, 291:2319-27.

Vlaicu R, Rus HG, Niculescu F, et al. 1985. Immunoglobulins and complement components in human aortic atherosclerotic intima. Atherosclerosis, 55:35-50.

Volanakis JE. 1982. Complement activation by C-reactive protein complexes. Ann NY Acad Sci, 389:235-50.

Volanakis JE, Kaplan MH. 1974. Interaction of C-reactive protein complexes with the complement system. II. Consumption of guinea-pig complement by CRP complexes: requirement for human Clq. J Immunol, 113:9-17.

Wang Y, Hu Q, Madri JA, et al. 1996. Amelioration of lupus-like autoimmune disease in NZB/WF1 mice after treatment with a blocking monoclonal antibody specific for complement component C5. Proc Natl Acad Sci U S A, 93(16):8563-8.

Ward PA. 2008. Role of the complement in experimental sepsis. J Leukoc Biol, 83:467-70.

Weiler JM. 1983. Polyions regulate the alternative amplification pathway of complement. Immunopharmacol, 6:245-55.

Weiler JM, Yurt RW, Fearon DT, et al. 1978. Modulation of the formation of the amplification convertase of $\mathrm{C} 3 \mathrm{~b}, \mathrm{Bb}$, by native and commercial heparin. J Exp Med, 147:409-21.

Weisman HF, Bartow T, Leppo MK, et al. 1990a. Recombinant soluble CR1 suppressed complement activation, inflammation, and necrosis associated with reperfusion of ischemic myocardium. Trans Assoc Am Physicians, 103:64-72.

Weisman HF, Bartow T, Leppo MK, et al. 1990b. Soluble human complement receptor type 1: in vivo inhibitor of complement suppressing post-ischemic myocardial inflammation and necrosis. Science, 249:146-51

Welch TR, Frenzke M, Witte D, et al. 2002. C5a is important in the tubulointerstitial component of experimental immune complex glomerulonephritis. Clin Exp Immunol, 130:43-8.

Wurzner R, Schulze M, Happe L, et al. 1991. Inhibition of terminal complement complex formation and cell lysis by monoclonal antibodies. Complement Inflamm, 8:328-40.

Yasuda M, Takeuchi K, Hiruma M, et al. 1990. The complement system in ischemic heart disease. Circulation, 81:156-63.

Zhang HF, Yu J, Bajwa E, et al. 1999. Targeting of functional antibody-CD59 fusion proteins to a cell surface. $J$ Clin Invest, 103:55-61.

Zhang H, Lu S, Morrison SL, et al. 2001. Targeting of functional antibody-decay-accelerating factor fusion proteins to a cell surface. $J$ Biol Chem, 276:27290-5. 
